\title{
Evaluation of RegCM 4.4 to Get Cloud and Monsoon Features with Seasons over India
}

\author{
Ruchita Shah, Rohit Srivastava, and Rohit Srivastava
}

\begin{abstract}
Global warming may affect sea level, precipitation patterns, heat waves, melting of glaciers, frequent droughts and storms which alter dynamics of earth-atmosphere system. Uneven precipitation pattern can be understood well by cloud processes with the help of cloud microphysical properties. These properties can be studied by various methods but model simulation plays a significant role as it can reproduce features with high spatial and temporal resolution. Such high resolution study may be done with the help of regional climate models. Study of cloud properties at high resolution is important for a country like India as almost $70 \%$ of the population depends on agriculture for their livelihood. Thus there is a need to understand monsoon variability to sustain economy of India. Present study tries to reproduce monsoon features over Indian subcontinent and adjoining regions to know the performance of regional climate model (RegCM4.4), which is essential to gain confidence in the model. For this purpose, a normal rainfall year 2010 is chosen to study monsoon features. Paper focuses to link the properties of cloud, precipitation and relative humidity to capture major features of the monsoon. Beginning of south-west monsoon over the Arabian Sea and north-east monsoon over the Bay of Bengal is captured well by the model. During pre-monsoon, initial phase of south-west monsoon is picked well with relative humidity $(80-100 \%)$ and cloud liquid water content $\left(0.4-1.8 \mathrm{~kg} \mathrm{~m}^{-2}\right)$ over the Arabian Sea. Also during post-monsoon, initial phase of north-east monsoon is captured with relative humidity $(80-100 \%)$ and cloud liquid water content $\left(0.2-1.2 \mathrm{~kg} \mathrm{~m}^{-2}\right)$ over the Bay of Bengal. Simulation of such dependent parameters may help to understand monsoon variability and may be applicable to tropical regions.
\end{abstract}

Index Terms-Climate change, cloud microphysical properties, monsoon, regional climate model.

\section{INTRODUCTION}

Model simulation is an actual representation of our earth-atmosphere system which helps to simulate climatic parameters. Simulation study is comparatively more beneficial as compared to in-situ as well as remote sensing method. In-situ measurements are more accurate and reliable, but limited with its spatial resolution and are less economic. Satellite data is limited with its temporal resolution as it repeats the same location over the globe. Thus, satellite and in-situ cannot capture each and every processes of

Manuscript received February 11, 2018; revised August 7, 2018.

Ruchita Shah and Rohit Srivastava are with the Department of Science, Pandit Deendayal Petroleum University, Raisan, Gandhinagar, Gujarat, India (e-mail: ruchitapshah05@gmail.com, rohit.prl@gmail.com).

Rohit Srivastava is with Indian Centre for Climate and Societal Impacts Research (ICCSIR), Mandvi, Kachchh, Gujarat, India (e-mail: rohitphy@gmail.com). earth-atmosphere system. As compared to both the methods, simulation works at good spatial as well as temporal resolution. Thus, simulation plays an important role in assessing climate variation at global and regional scale.

Nowadays, weather patterns are changing at small scale, which is not captured by global models. This creates a need of model which runs with high spatial resolution. Models can be categorized into two types: Global Climate Model and Regional Climate Model. Global climate model incorporates most of the parameters related to ocean-atmosphere system whereas regional climate model incorporates most of the parameters related to some particular region. Thus regional model runs with high accuracy as compared to global model. Heterogeneity in the system could be identified more accurately with regional climate model. Also, global climate model needs high computational facilities as compared to regional climate model. Atmospheric Global Circulation Model (AGCM) and Atmospheric - Ocean Global Circulation Model (AOGCM) were not able to resolve the cloud features at regional scale due to their coarse resolution [1]. Thus, there regional climate models are developed to understand climate processes and seasonal variability at regional scale. Generally, downscaling methods are used to catch and assess the impact of parameters. Simulated parameters with their features may help to represent the real system.

Regional climate model represent climatic information at fine scale, which help to regulate the configuration of climate variable. Earlier research study demonstrated that regional climate models are more reliable than global climate model to examine weather and climate conditions [1]. To understand uneven precipitation patterns for monsoon dominated region is important as it highly depends on precipitation. Almost $70 \%$ of the population depends on precipitation for their livelihood. Hence, there is a need to understand uneven precipitation patterns for Indian subcontinent. Various studies have conducted such experiments during last decade to evaluate the performance of regional climate model over South Asia [1]. Moreover, Indian summer monsoon gets simulated by various regional climate models and its observed climatology poses a great challenge due to its diversified climate [1-6]. Seasonal scale model simulations of Indian summer monsoon has reproduce monsoon characteristics for a decade 2000-2009 using Advanced Research Weather Research and Forecasting (ARW) [7].

Current study aims to know the performance of Abdus Salam International Centre for Theoretical Physics (ICTP) regional climate model version 4.4 (hereafter denoted as $\mathrm{RegCM})$. It is the fourth generation of regional climate model and an improved version of RegCM3 in terms of including various physics related schemes such as convection schemes 
over ocean and land, ocean-air exchanges, planetary boundary layer, radiative transfer, land types and surface processes [8], [9]. Modified radiative scheme in RegCM represents cloud for clear - sky as well as for cloudy conditions, which signify the situations more realistic. Sigma-p regional climate model runs on the hydrostatic version, which is same as that of the Mesoscale Model version 5 (MM5) of the NCAR (National Center for Atmospheric Research)/PSU (Pennsylvania State University) [10]. RegCM with standard 18 levels, has ability to simulate south west monsoon and associated precipitation features over India [11]-[13].

The objective of present study is to assess cloud features along with precipitation features as cloud is source of precipitation. Similarly, features of relative humidity are also to be assessed along with cloud as humidity is the major parameter in cloud formation and hence precipitation. Cloud microphysical properties such as Cloud Liquid Water Content (CLW) play a vital role to understand cloud processes [14]. To represent cloud and precipitation features, CLW and Precipitation Flux are reproduced respectively. Thus, precipitation along with its source parameter (i.e. cloud) and cloud with its source parameter (i.e. relative humidity) are simulated to know the performance of RegCM. Further, study tries to represent their relation with the help of simulated parameters.

\section{DATA AND Methodology}

\section{A. Model Description}

The idea of regional climate model was originally proposed to understand current varying conditions [15], [16]. The concept of downscaling was implemented in which large scale meteorological fields from global climate model runs which provide initial and time dependent lateral boundary conditions for high resolution regional climate model simulations. The first generation of regional climate model (RegCM1) was built upon Mesoscale Model version MM4 in the late 1980s [15], [17]. The dynamical core of RegCM1 is similar to that of the hydrostatic version of MM5 [10]. It includes the Biosphere-Atmosphere Transfer Scheme (BATS) for surface process and radiative transfer scheme of the National Center for Atmospheric Research (NCAR) Community Climate Model version (CCM1) [18]. The first major upgrade of RegCM was documented in terms of physics and numerical schemes and resulted in second generation of RegCM (RegCM2) [19]. The physics of RegCM2 was based on NCAR CCM2 and mesoscale model MM5 [10]. In this CCM2 package, radiative transfer package was used for radiative calculations and the latest version of BATS1E was added in the model [20]. Further, there were several improvements, addition and implementation of various schemes implemented and switching towards the latest version of the model RegCM4.4 [18]. Changes in the physics of the model which include a new large scale cloud and precipitation scheme. It accounts for the sub grid variability of clouds, new parameterizations for ocean surface fluxes and various cumulus convection scheme [21], [22]. In addition, global reanalysis datasets such as NCEP are used for initial and boundary conditions. The interfaces to the global atmospheric general circulation model (HadAM3H, NCAR, CCM3, etc.) are also available for coupling of Atmospheric Global Climate Model (AGCM) with RegCM.

\section{B. Data and Simulation Setup}

RegCM can be applied over different geographical regions and can adopt various parameterization schemes. It is used to reproduce monsoon features over India as India is such a country which is highly dependent on monsoon. The simulation conducted for a normal rainfall year-2010, to know the actual performance of RegCM. Present study aims to capture monsoon features with seasonal variation. For the sake of simplicity, only a month from each season has been selected (i.e. May for pre-monsoon, August for monsoon and October for post-monsoon season). For the present study, RegCM covers a region of $63^{\circ} \mathrm{E}-96^{\circ} 5^{\prime} \mathrm{E}$ to $5^{\circ} \mathrm{N}-33^{\circ} 5^{\prime} \mathrm{N}$ which includes Indian subcontinent and its adjoining oceanic regions. The model configured with a single domain of horizontal resolution of $60 \mathrm{~km}, 18$ vertical levels and with model top at $50 \mathrm{hPa}$. Initial atmospheric fields and time varying boundary conditions are derived from the National Centers for Environmental Prediction (NCEP) Reanalysis (NNRP1) with the grid of $2.5^{\circ} \times 2.5^{\circ}$. RegCM consists of various equations such as horizontal-momentum, continuity, thermodynamic and hydrostatic equations to model mathematically the physical conditions of the problem.

To confine planetary boundary layer (PBL), Holtslag scheme was applied based on non-local diffusion concept with normal mercator mapping projection [23]. Earlier study has shown that this scheme to represent PBL was processed with various modifications and its new version was implemented in RegCM [23]. There are various convection schemes, among them Grell convective scheme was implemented, as it has performed better than other convection schemes to simulate south west monsoon [3, [24]. Arakawa and Schubert closure assumption scheme was adopted to stabilize the environment [25]. Grell scheme was designed with steady state circulation of a cloud i.e. a downdraft and an updraft. No mixing with atmospheric gases is allowed and hence no entrainment and detrainment takes place at the edges of the cloud. Such mixing is allowed at the top and bottom of the cloud, as cloud initiates its formation from bottom side and upward movement of the cloud includes upper section of the cloud. This scheme gets triggered when moist convective level is achieved by the parcel.

\section{RESULT AND DISCUSSION}

It is important to know the accuracy of the model before applying RegCM for future projection studies. It becomes important to evaluate the observed regional climate characteristics. Simulation results of relative humidity, CLW and precipitation flux may help to understand initial and final phase of cloud formation processes. Present study aims to know the performance of RegCM by simulating features of defined parameters- relative humidity, CLW and precipitation flux with seasonal variation (pre-monsoon, monsoon and post-monsoon season). 


\section{A. Relative Humidity}

The model simulation of monthly mean relative humidity at $850 \mathrm{hPa}$ has been shown in Fig. 1a-c. During a pre-monsoon month of May, oceanic regions are comparatively more humid than land (Fig. 1a). Cyclonic structure over central the Arabian Sea is picked, which shows the beginning of south west monsoon. Relative humidity ranges from 40-90\% over the Bay of Bengal and Peninsular India, whereas 30-80\% humidity is covered by almost north India. Southern region of India is more humid than northern region, which is may be due to pre-monsoon season. Humidity ranges from $60-90 \%$ is reproduced over peninsular India, lower Western Ghats, Eastern Ghats and most of the eastern region of India, as it may developed the initial phase of south-west monsoon. Wind drives moisture from the Arabian Sea onto the land region, which is picked well by the model.

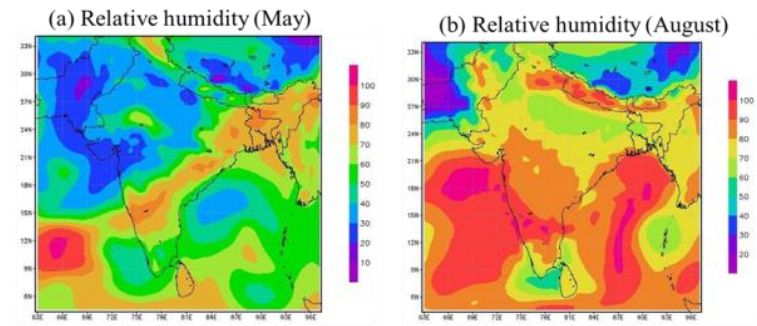

(c) Relative humidity (October)

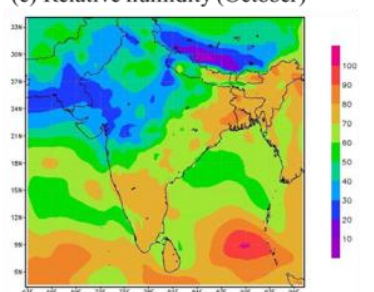

Fig. 1. Relative humidity (\%) at $850 \mathrm{hPa}$ for (a) pre-monsoon (May) (b) monsoon (August) and (c) post-monsoon (October) of the year 2010.

During the month of August, relative humidity (70-100\%) has reproduced over whole Indian region. The wind transports the seasonal moisture onto land regions which is well captured by the model (Fig. 1b). Almost whole Arabian Sea and central Bay of Bengal is simulated with $90 \%$ relative humidity, which demonstrates monsoon season. High relative humidity is developed over coastal region of southern Gujarat, mid Bay of Bengal, some portions of Western Ghats and peninsular India. Also, it ranges from $70-90 \%$ over central India. Thus monsoonal features is captured well by the model.

Cyclonic structure of relative humidity rolled over from the Arabian Sea onto the Bay of Bengal, which signifies end of south west monsoon (end of monsoon season) and initial phase of north-east monsoon (start of post-monsoon) (Fig. 1c) Peninsular region of India captures with by more moisture as compared to other land regions, because during this period the moisture drives over this region. Low level of relative humidity is developed over north India and upper central India whereas the Arabian Sea which gets captured with $60-90 \%$ humidity. Among all the regions of India, lowest humidity (10-30\%) gets simulated over southern region of Rajasthan and Indo - Gangetic plains. Most of the land regions developed with low relative humidity, which depicts the post-monsoon season. Hence, almost all the seasonal features of relative humidity gets captured well by the model.

\section{B. Total Columnar Cloud Liquid Water Content (CLW):}

Same as relative humidity during May, total column CLW is also picked higher over oceans as compared to land. High CLW gets reproduced over the Arabian Sea and central Bay of Bengal. These oceanic regions matches well with relative humidity (Fig. 1a). It signifies that these regions contain more moisture, which may increase droplet concentration. This in turn may increase CLW as observed in Fig. 2a. Prevailing condition of precipitation clouds reproduced well by RegCM, especially over oceans. Central India consists of mid-level $(30-70 \%)$ of relative humidity (Fig. 1a), which correlates positively with mid-level $\left(0.2-1.4 \mathrm{~kg} \mathrm{~m}^{-2}\right)$ of CLW (Fig. 2a). Small portions of east India reproduces high amount of CLW $\left(0.6-2 \mathrm{~kg} \mathrm{~m}^{-2}\right)$, which has high range of relative humidity (80-90\%). Such correlation result also reproduce over north India with small patches. But somehow, model is not able to capture cloud features over peninsular India and eastern region, which were clearly captured by relative humidity.
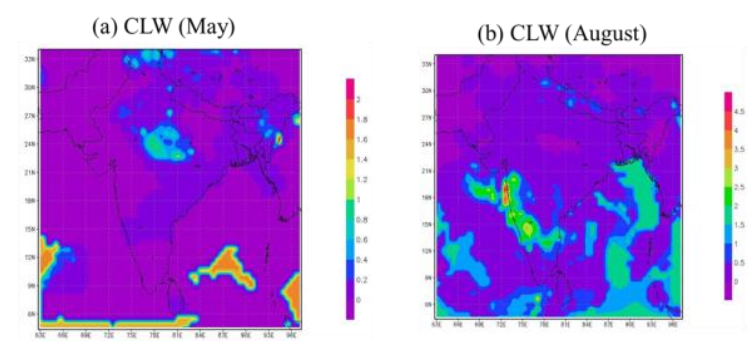

(c) CLW (October)

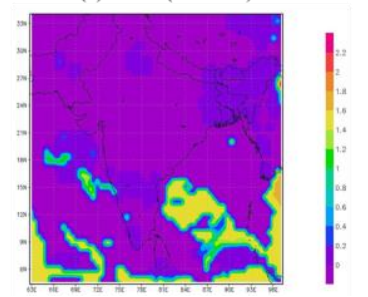

Fig. 2. Total column cloud liquid water content (CLW) in $\mathrm{kg} \mathrm{m}^{-2}$ is simulated for (a) pre-monsoon (May) (b) monsoon (August) and (c) post-monsoon (October) of the year 2010.

Most of the cloud forms over oceans during monsoon, which gets captured well by the model (Fig. 2b). The defined correlation between relative humidity and CLW play strongly over mid Bay of Bengal, whereas weakly over the Arabian Sea. High range ( 1 to $4.5 \mathrm{~kg} \mathrm{~m}^{-2}$ ) of CLW is developed over Western Ghats, which shows good correlation with relative humidity. It is also correlating well over oceanic region of southern Gujarat. Moreover, mid-level (1-3.5 $\mathrm{kg} \mathrm{m}^{-2}$ ) of CLW and relative humidity are associated at the southern - most tip of India. Almost all the features of monsoon show prominent results and developed well by RegCM.

During post-monsoon month of October, almost whole India reproduces with low range of CLW or cloud less conditions, which gets captured well by the model. The defined correlation between relative humidity and CLW play significantly to indicate north-east monsoon over the Bay of Bengal (Fig. 2c). On the other hand, low level of relative humidity (Fig. 1c) over southern Rajasthan may form cloud with lowest amount $\left(0.2 \mathrm{~kg} \mathrm{~m}^{-2}\right)$ of CLW, which is observed. Hence, post monsoon features show that RegCM may performs better in simulating cloud features as well as in correlation with relative humidity. 


\section{Total Rain Precipitation Flux}

Seasonal variation of total column rain precipitation flux is shown in Fig. 3(a-c). Almost whole India including the Arabian Sea and the Bay of Bengal reproduces with low range $\left(0-2 \times 10^{-4} \mathrm{~kg} \mathrm{~m}^{-2} \mathrm{~s}\right)$ of precipitation, which is may be due to pre-monsoon season (Fig. 3a). Further increase in CLW may increase precipitation flux. Precipitation flux covering peninsular region, Eastern Ghats and some portion of east India get matches well with relative humidity (Fig. 1a) and CLW (Fig. 2a). Same scenario also gets captured over Gujarat and its nearby region with low range of relative humidity, CLW and precipitation flux. On the other hand, high range precipitation flux reproduces over eastern region of India, which matches with relative humidity (Fig. 1a), but not with CLW (Fig. 2a).
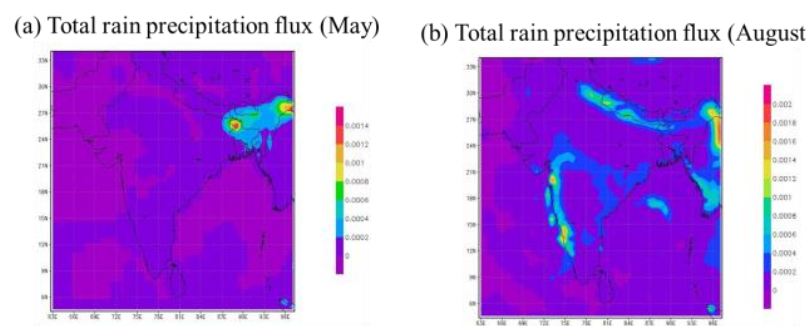

(c) Total rain precipitation flux (October)

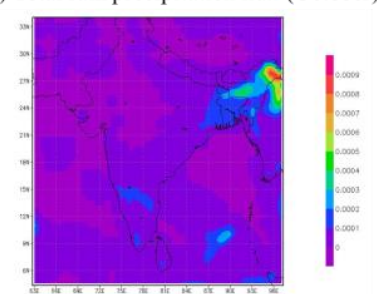

Fig. 3. Total column rain precipitation flux in $\mathrm{kg} \mathrm{m}^{-2} \mathrm{~s}$ is simulated for (a) pre-monsoon (May) (b) monsoon (August) and (c) post-monsoon (October) from RegCM of the year 2010.

Almost all the regions of India gets reproduced with precipitation flux of about $2 \times 10^{-4} \mathrm{~kg} \mathrm{~m}^{-2} \mathrm{~s}$, as shown in Fig. $3 \mathrm{~b}$. Land regions are comparatively captured with high precipitation flux than oceanic regions, which represent the monsoon season and captured well by RegCM. Western Ghats gets reproduced by high range of precipitation flux $\left(4 \times 10^{-4}-1.6 \times 10^{-3} \mathrm{~kg} \mathrm{~m}^{-2} \mathrm{~s}\right)$, show positive relation with relative humidity and CLW. Similar trends also captured over Eastern Ghats but with low range values. Small patches of precipitation flux over nearby areas of Indo-Gangetic plains are developed with same dependency. In the same way, most of the eastern part is reproduced with high precipitation flux but gets confined over small region. Overall, model performs better to show features of CLW during monsoonal month of August.

Same as CLW, almost all the regions of India captures with low amount of precipitation flux (Fig. 3c). The range of precipitation flux over eastern region has decreased which is comparable with Fig. $3 b$ and $3 c$, which demonstrates post monsoon season. The Bay of Bengal gets influenced with more flux as compared to the Arabian Sea, which is same as of relative humidity and CLW (Fig. 1c and Fig. 2c respectively). Formation of precipitation flux has started in the Bay of Bengal which signifies the north-east monsoon, same as estimated with relative humidity and CLW. No precipitation flux reproduced over Gujarat, Rajasthan and some portion of central India, which matches well with CLW (Fig. 2c) and relative humidity (Fig. 1c). Hence, RegCM captures almost all the features of post-monsoon features as well as their seasonal variation.

\section{SUMMARY}

Present study tries to know the performance of monsoon features with relative humidity, CLW and precipitation flux. Simulation was conducted over India for pre-monsoon, monsoon and post-monsoon season of normal rainfall year to assess the model with normal conditions. Grell with Arakawa and Schubert closure scheme was adopted to reproduce relative humidity (at $850 \mathrm{hPa}$ ), total column CLW and total column precipitation flux. The model could reproduce seasonal features of precipitation flux during pre-monsoon $\left(0-2 \times 10^{-4} \quad \mathrm{kgm}^{-2} \mathrm{~s}\right)$, monsoon $\left(2 \times 10^{-4} \mathrm{kgm}^{-2} \mathrm{~s}\right)$ and post-monsoon $\left(1 \times 10^{-4} \mathrm{~kg} \mathrm{~m}^{-2} \mathrm{~s}\right)$ season. All the three simulated parameters demonstrate almost all the seasonal features of monsoon. Simulation features of south-west monsoon and north-east monsoon gets captured well by the model. Rise in relative humidity leads to distribute more moisture to aerosol, may result in high concentration of cloud droplets which in turn increase CLW and hence precipitation flux. This dependency captured well by RegCM over peninsular region, Eastern Ghats, some portion of east India, Gujarat and nearby region for pre-monsoon season. In the same way, this relation gets visualize over Western Ghats and over Eastern Ghats for monsoon season and over Gujarat, Rajasthan and some portion of central India for post-monsoon season. Further work is going on to improve simulation schemes in order to get cloud and monsoon features over land regions. Such study of simulating source parameters may help to estimate the future climate studies at a great extent.

\section{REFERENCES}

[1] M. Hassan, D. Penfei, W. Iqbal, W. Can, F. Wei, and W. Ba, "Temperature and precipitation climatology assessment over South Asia using the regional climate model (RegCM4.3): An evaluation of the model performance," Journal of Earth Science and Climate Change, vol. 5, 2014.

[2] C. V. Srinivas, D. H. Prasad, D. V. B. Rao, R. Baskaran, and B. Venkatraman, "Simulation of the Indian summer monsoon onset-phase rainfall using a regional model," Annales Geophysicae, vol. 33, pp. 1097-1115, 2015.

[3] K. Pattnayak, S. K. Panda, and S. K. Dash, "Annual cycles of circulation and precipitation over India simulated by a regional climate model," Vayumandal, vol. 38, pp. 35 - 45, 2014

[4] K. K. Kumar, S. K. Patwardhan, A. Kulkarni, K. Kamala, K. K. Rao, and R. Jones, "Simulated projections for summer monsoon climate over India by a high-resolution regional climate model (PRECIS)," Current Science, vol. 101, 2011.

[5] E. Lioubimtseva, "Physical geography of northern Eurasia," Oxford: Oxford University Press, 2002, pp. 267-283.

[6] F. Syed, W. Iqbal, A. Syed, and G. Rasul, "Uncertainties in the regional climate models simulations of South-Asian summer monsoon and climate change," Climate Dynamics, vol. 42, pp. 2079-2097, 2013.

[7] C. V. Srinivas, D. Hariprasad, D. V. Bhaskar Rao, Y. Anjaneyulu, B. Baskaran, and B. Venkatrman, "Simulation of the Indian summer monsoon regional climate using advanced research WRF," International journal of Climatology, vol. 33, 2012.

[8] J. S. Pal, F. Giorgi, X. Bi, N. Elguindi, F. Solmon, X. Gao, R. Francisco, A. Zakey, J. Winter, M. Ashfaq, F. S. Syed, L. C. Sloan, J. L. Bell, N. S. Diffenbaugh, J. Karmacharya, A. Konaré, D. Martinez, R. P. da Rocha, and A. L. Steiner, "Regional climate modeling for the developing 
world: the ICTP RegCM3 and RegCNET," Bullet of the American Meterological Society, vol. 88, pp. 1395 - 1409, 2007.

[9] G. Alexandri, A. K. Georgoulias, P. Zanis, E. Katragkou, A Tsikerdekis, K. Kourtidis, and C. Meleti, "On the ability of RegCM4 regional climate model to simulate surface solar radiation patterns over Europe: An assessment using satellite-based observations," Atmospheric Chemistry and Physics, vol. 15, pp. 13195-13216, 2015

[10] G. Grell, J. Dudhia, and D. Stauffer, "A description of the fifth generation Penn State/NCAR mesoscale model (MM5)," 1994.

[11] A. P. Dimri, "Impact of subgrid scale scheme on topography and landuse for better regional scale simulation of meteorological variables over the Western Himalayas," Climate Dynamics, vol. 32, pp. 565-574, 2009.

[12] P. Sinha, U. C. Mohanty, S. C. Kar, S. K. Das, U. C. Mohanty, S.C. Kar S. K. Dash, and S. Kumari, "Sensitivity of the GCM driven summer monsoon simulations to cumulus parameterization schemes in nested RegCM3," Theortical Applied Climatology, vol. 112, pp. 285-306, 2013a.

[13] P. Sinha, U. C. Mohanty, S. C. Kar, and S. Kumari, "Role of the Himalayan orography in simulation of the Indian summer monsoon using RegCM3," Pure and Applied Geophysics, 2013.

[14] S. Zeng, J. Riedi, C. R. Trepte, D. M. Winker, and Y.-X. Hu, "Study of global cloud droplet number concentration with A-Train satellites," Atmospheric Chemistry and Physics, vol. 14, pp. 7125-7134, 2014.

[15] R. E. Dickinson et al., "A regional climate model for the western United States," Climate Change, vol. 15, 1989.

[16] F. Giorgi, "Simulation of regional climate using a limited area model nested in a general circulation model," Journal of Climatology, vol. 3 , 1990.

[17] F. Giorgi, "The climatological skill of a regional model over complex terrain," Mon. Wea. Rev., vol. 117, pp. 2325-2347, 1989.

[18] R. E. Dickinson et al., "Bio-sphere Atmosphere Transfer Scheme (BATS) version 1e as coupled to the NCAR community climate model," 1993.

[19] F. Giorgi et al., "Development of a second generation regional climate model (RegCM2). I. Boundary layer and radiative transfer processes," Mon Weather Rev., vol. 121, 1993a.

[20] B. P. Briegleb, "Delta-Eddington approximation for solar radiation in the NCAR community climate model," Journal of Geophysical Research, vol. 97, pp. 7603-7612, 1992.

[21] J. S. Pal et al., "Simulation of regional-scale water and energy budgets: representation of sub grid cloud and precipitation processes within RegCM," Journal of Geophysical research, vol. 105, pp. 29579-29594, 2000

[22] X. Zeng, M. Zhao, and R. E. Dickinson, "Intercomparison of bulk aerodynamic algorithms for the computation of sea surface fluxes using toga coare and tao data," Journal of Climate, vol. 11, pp. 2628-2644, 1998.

[23] A. C. M. Beljaars and A. A. M. Holtslag, "Flux parameterization over land surfaces for atmospheric models," American Meterological Society, 1990.

[24] G. A. Grell, "Prognostic evaluation of assumptions used by cumulus parameterization," Mon. Wea. Rev., vol. 121, pp. 764-787, 1993.

[25] A. Arakawa and W. H. Schubert, "Interaction of a cumulus cloud ensemble with large-scale environment," Journal of Atmospheric Science, vol. 31, pp. 674-701, 1974.

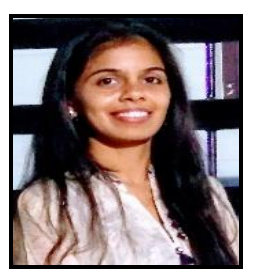

Ruchita Shah is at present pursuing her Ph.D. in the field of atmospheric science from Pandit Deendayal Petroleum University (PDPU), Gandhinagar, Gujarat, India. Her thesis aims to work with cloud microphysical properties to understand cloud and rain processes. She participated and presented in four national conferences and one international conference where she learned about cloud processes, rain formation, effect of global warming on atmospheric parameters and climate change.

In 2015, she received her degree of master in Physics from PDPU. She also did her internship at Gujarat Energy Management Institute (GERMI), Gandhinagar, India in the field of solar cell. She opted an experimental work in which she fabricated and optimized an organic - inorganic solar cell with good efficiency. Later on, her work presented as a poster in Material Research Society (MRS) Fall Meeting at Boston, MA, USA in 2016.

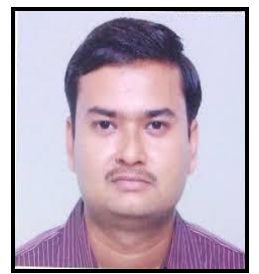

Rohit Srivastava at present is working as an associate professor in Pandit Deendayal Petroleum University (PDPU), Gandhinagar, Gujarat, India. He received his Ph.D. from Physical Research Laboratory (PRL), Ahmedabad, India awarded by MLSU, Udaipur in the year 2009. After completion of Ph.D., he did PDF from PRL in 2009-10. His research areas of interest are cloud microphysics, characterization and modeling of cloud formation processes using stable isotopes, atmospheric water vapor cycle, study of isotopic equilibrium/disequilibrium between water and vapor over ocean surface and during rain over land.

He has published many papers in peer-reviewed journals along with national and international conferences. He participated in several scientific cruises during the year 2006 - 2009 to understand monsoon dynamics. Among them two ship cruises to Antarctica, wherein in one of them, he was deputed as Chief Scientist of the expedition 2009.

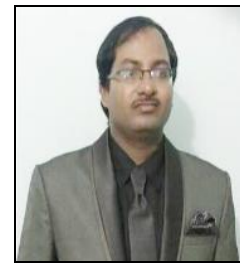

Rohit Srivastava did his Ph.D. on atmospheric aerosols and their optical and radiative properties from Physical Research Laboratory (PRL), Ahmedabad. He did his post-doc from Space and Atmospheric Sciences Division of PRL. Presently, he is assistant professor at Indian Centre for Climate and Societal Impacts Research (ICCSIR), Mandvi, Kachchh, Gujarat.

He has successfully completed two scientific projects of Ministry of Earth Science (MoES) and Department of Science and Technology (DST). He has participated in different national level cruise campaigns for air pollution measurements. He has good experience in running regional climate model on high-performance computing clusters (HPCs). He has developed a model to estimate aerosol properties in different mixing states. He is the lifetime member of Indian Society of Remote Sensing (ISRS), Indian Meteorological Society (IMS) and Indian Aerosol Science and Technology Association (IASTA). 